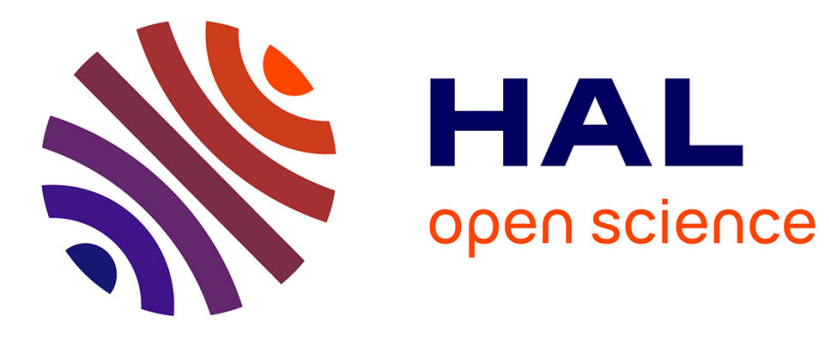

\title{
Measurement and modelling of chemical shrinkage of vinyester composites
}

Yasir Nawab, Nicolas Boyard, Vincent Sobotka, Pascal Casari, Frédéric

Jacquemin

\section{- To cite this version:}

Yasir Nawab, Nicolas Boyard, Vincent Sobotka, Pascal Casari, Frédéric Jacquemin. Measurement and modelling of chemical shrinkage of vinyester composites. 15th International ESAFORM Conference on Material Forming, 2012, Nuremberg, Germany. 10.4028/www.scientific.net/KEM.504-506.1129 . hal-01008395

\section{HAL Id: hal-01008395 \\ https://hal.science/hal-01008395}

Submitted on 15 Apr 2019

HAL is a multi-disciplinary open access archive for the deposit and dissemination of scientific research documents, whether they are published or not. The documents may come from teaching and research institutions in France or abroad, or from public or private research centers.
L'archive ouverte pluridisciplinaire HAL, est destinée au dépôt et à la diffusion de documents scientifiques de niveau recherche, publiés ou non, émanant des établissements d'enseignement et de recherche français ou étrangers, des laboratoires publics ou privés. 


\title{
Measurement and modelling of chemical shrinkage of thermoset
}

\section{composites}

\author{
Yasir Nawab ${ }^{1,2, a}$, Nicolas Boyard ${ }^{1, b}$, Vincent Sobotka $a^{1, c}$, Pascal Casari ${ }^{2, d}$, \\ Frédéric Jaquemin ${ }^{2, e}$ \\ ${ }^{1}$ Université de Nantes, CNRS, Laboratoire de Thermocinétique de Nantes, UMR 6607, La \\ Chantrerie, rue Christian Pauc, BP 50609, 44306 Nantes cedex 3 - France \\ ${ }^{2}$ Université de Nantes, Institut de Recherche en Génie Civil et Mécanique, UMR CNRS 6183, 37 \\ boulevard de l'Université, BP406, 44600 Saint-Nazaire, France \\ ayasir.nawab@univ-nantes.fr, ${ }^{\mathrm{b}}$ nicolas.boyard@univ-nantes.fr, ${ }^{\mathrm{c}}$ vincent.sobotka@ univ-nantes.fr,

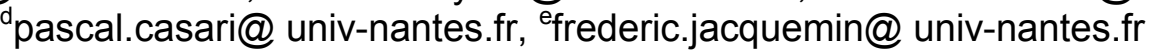

Keywords: PVT- $\alpha$ mould, Chemical shrinkage, Thermal gradients, Kinetics law

\begin{abstract}
Knowledge of resin chemical shrinkage is crucial for the determination of residual strains, stresses and warpage of composite parts during curing. Shrinkage measurement is more accurate on several millimetre thick samples. However, in that case thermal properties of resin and the strong coupling between thermoset chemical reactions (generally rapid and strongly exothermal) and thermal fields lead to non-negligible thermal and curing gradients in the piece. It is then necessary to take these variations into account to have an accurate description of the shrinkage. In the present study, a home-built device "PVT- $\alpha$ " mould is used to measure the volume variation of vinylester resin and associated composites during the curing and then shrinkage is identified by considering these gradients. The results demonstrate that a linear evolution of the shrinkage with the conversion degree is a good model to describe the chemical effect on the global volume behavior of the piece. The contribution of chemical and thermal effects on the volume curve is quantified.
\end{abstract}

\section{Introduction}

During the curing cycle, the thermoset composite undergoes the residual deformations and stresses due to shrinkage of matrix. This shrinkage may have a thermal and/or chemical origin. The chemical shrinkage is a direct consequence of crosslinking of the thermosetting polymer. Resulting residual stresses can lead to dimensional instability, warpage, ply cracking, delamination and fibre buckling. Characterization of the shrinkage is thus of crucial interest for stress calculation and modelling purposes. However, the evolution and quantification of chemical shrinkage are still a partially understood phenomenon. Coupling of thermal and chemical changes in matrix, thermal gradients, rapid and exothermic chemical reactions make the determination of chemical shrinkage difficult. Problem becomes more complex in case of composites as fibres resist the dimensional changes.

The available approaches for measuring volume changes during curing can be classified mainly as volume dilatometry and non-volume ones [1]. Plunger type dilatometers based on volume dilatometry are the mostly used for thermosets due to their working in the industrial like conditions, i.e. high pressure, and temperature ramp conditions. As shrinkage is often expressed as a function of reaction conversion degree, another instrument, e.g. DSC is required along with a dilatometer. The measurement using two instruments can be prejudicial as the conditions of test may not be the same. In order to overcome such problem, a multifunctional device called PVT- $\alpha$ mould was built, which can measure volume changes during curing, heat flux hence degree of cure, and surface temperature for a given hydrostatic pressure. 
During the curing, volume variation of the part is the result of coupled thermal and chemical contributions. Due to the strong coupling between heat transfers and reaction kinetics and low thermal diffusivity of resin, gradients of temperature exist through the thickness and have to be considered to compute thermal contribution. Moreover, the temperature field has to be computed according to volume variation and implies to propose a model describing the cure shrinkage.

In the present study, some results on thermokinetic characterization and cure shrinkage of an epoxy vinylester resin and associated cross-ply glass fibre (UD) composites are presented. The contributions of thermal expansion and chemical shrinkage on the experimental displacement curve during the curing cycle are then deduced from thermal and curing fields. They are computed by solving a 1D conduction problem with a moving boundary and volume variation equation coupled to crosslinking kinetics assuming a shrinkage model. The calculated shrinkage at the end of reaction is very close to experiments. Finally, an effect of fibres on chemical shrinkage has been highlighted.

\section{Material and methods}

Vinylester resin (DERAKANE MOMENTUM 411-350 epoxy vinyl ester) was used with $0.05 \mathrm{wt} \%$ of initiator (Cobalt Naphthenate) and $1 \mathrm{wt} \%$ of Catalyst (NOROX MEKP-925H Methylethylketone peroxide (MEKP)). These proportions were selected to get maximum gel time at room temperature $\left(30 \pm 10 \mathrm{~min}\right.$ at $\left.25^{\circ} \mathrm{C}\right)$. Unidirectional glass fibre having surface density of 300 $\mathrm{g} / \mathrm{m}^{2}$ was used as reinforcement [0/90] in composite. Two fibre volume fractions $(32 \mathrm{vol} \%$ and $49 \mathrm{vol}$ $\%$ ) were selected to study the effect of the fibre fraction on shrinkage. The following thermal cycle was used for the curing of samples in PVT- $\alpha$ mould at the pressure of $0.65 \mathrm{MPa}$.

1. Equilibrate the system at room temperature and maintaining for $2 \mathrm{~min}$.

2. Heating to $180^{\circ} \mathrm{C}$ at rate of $4^{\circ} \mathrm{C} / \mathrm{min}$ and isothermal step for $10 \mathrm{~min}$ at that temperature.

3. Cooling to room temperature at $4{ }^{\circ} \mathrm{C} / \mathrm{min}$.

Description of PVT- $\alpha$ mould. The PVT- $\alpha$ mould is devoted to study neat thermosetting resin and composites during and/or after curing cycle. In addition, experiments can be done on bulk samples (several millimetre thick and $40 \mathrm{~mm}$ diameter). The instrument can achieve an adjustable pressure up to $10 \mathrm{MPa}$ in moulding cavity and temperature up to $200^{\circ} \mathrm{C}$. It consists of a piston which can move in a cylindrical stainless steel cavity (Fig.1.). The mould is designed so that heat transfers are 1D through the sample thickness. The heating is ensured by three heaters located at the top and bottom to heat the piston and cavity respectively. Two heat flux sensors are placed in the bottom of the mould and in the piston. More details about this device are given in [2]. Data treatment with a Beck inverse sequential algorithm [3] provides temperature and heat flux density at the surface of the sensor, exchanged between the sample and the mould.

Resin/composite samples are sealed in deformable but incompressible elastomer capsule to avoid the jamming of the mould. Capsule is then placed in PVT- $\alpha$ cavity under the piston which moves following the variations of the sample volume to get a constant hydrostatic pressure, which are recorded by LVDT-type displacement sensor with a precision of $1 \mu \mathrm{m}$ and a limit of $10 \mathrm{~mm}$. As surface of the elastomer on which the pressure is applied does not vary so the measured thickness is directly related to the sample volume and its variations.

\section{Thermo-physical characterisation of the resin}

Thermo-physical properties of resin are required for the modelling purpose. Thermal conductivity $(\lambda)$ is found between $25^{\circ} \mathrm{C}$ and $75^{\circ} \mathrm{C}$ by guarded hot plate method [4]. A second technique, based on an optimization approach, is also applied to determine the thermal conductivity in both uncured and cured states [5]. By using DSC (TA Q200 from TA Instruments $\left.{ }^{\circledR}\right)$, total heat of cure (324.9 \pm 3.6 $\mathrm{J} / \mathrm{g}$ ), glass transition temperature Tg and specific heat in liquid and cured states are determined. The glass transition temperature $\mathrm{Tg} 0$ of uncured and $\mathrm{Tg} \infty$ fully cured resin are found equal to $-55.5^{\circ} \mathrm{C}$ and $118.9^{\circ} \mathrm{C}$ respectively. Relationship between $\mathrm{Tg}$ and conversion degree $\alpha$ is found by using the classical model developed by Pascault and Williams [6]. A model (2b) is also proposed to define the kinetics of curing reaction. 


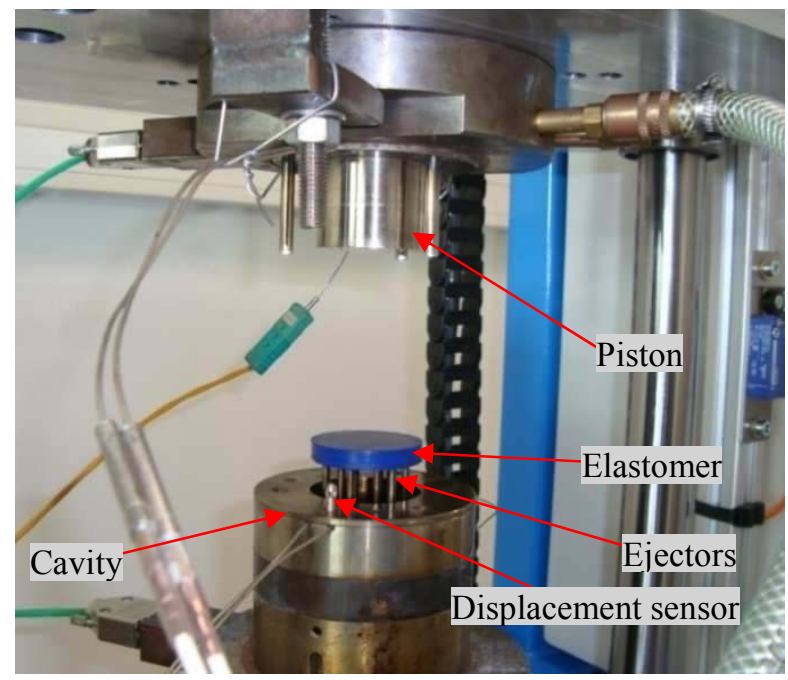

Fig. 1. General view of PVT- $\alpha$ device.

\section{Determination and modelling of the resin cure shrinkage}

The acquisition system of mould PVT- $\alpha$ records the signals given by the six thermocouples of both heat flux sensors with respect to a cold junction and the signal of the displacement sensor. A reference experiment was performed on an aluminium disc with known properties placed in the elastomer capsule by passing through the same thermal cycle as the sample, in order to take into account the possible heat losses of the mould, and thermal expansions of LVDT sensor, elastomer and the mould. After data treatment, total heat flux density $(\varphi)$, surface temperature and the thickness variation are obtained.

A typical evolution of the thickness (volume) variation of the resin during the thermal cycle and the associated heat flux data (heating step) are presented in Fig. 2. During the heating cycle, this thickness variation is the result of thermal expansion and chemical shrinkage while the only prominent phenomenon during cooling cycle is the thermal contraction.

Linear (A-B) part of the thickness curve represents the thermal expansion of neat resin. Since the reaction starts at a low temperature, this region is very small, and it is difficult to determine accurately the coefficient of thermal expansion (CTE) of uncured resin. In the region between the points $\mathrm{B}$ and $\mathrm{C}$, the chemical shrinkage of resin also appears in addition to thermal expansion and tends to decrease the sample thickness up to the point $\mathrm{C}$ where the resin is close to be fully cured. After the point $\mathrm{C}$, the only prominent effect is again thermal expansion so a linear behaviour of the displacement curve is observed between points $\mathrm{C}$ and $\mathrm{D}$.

Thickness decreased from point $\mathrm{D}$ to $\mathrm{F}$ during cooling step. However, between points $\mathrm{C}$ and $\mathrm{E}$, the resin goes through the glass transition from the rubbery to glassy state as the curve slope changes. The difference between points $\mathrm{A}$ and $\mathrm{F}$ gives the total shrinkage of matrix $(-2.1 \mathrm{vol} \%)$ at room temperature after curing and cooling. In order to get value of CTE at each time step in the region $\mathrm{B}-\mathrm{C}$, a mixing law (1) can be used, where $\mathrm{CTE}_{\text {uncured }}$ and $\mathrm{CTE}_{\text {rubbery }}$ are identified from a heat-transfer model presented in next section.

$$
\operatorname{CTE}(\alpha)=\operatorname{CTE}_{\text {uncured. }}(1-\alpha)+\alpha \cdot \operatorname{CTE}_{\text {rubbery }}
$$

In the beginning, when the reaction did not start, an endothermal effect (heat flux curve, Fig. 2.) can be observed due to the heating of the sample. However, as the temperature increased, the reaction started, resulting in exothermal peak. At about $118^{\circ} \mathrm{C}$, the resin is fully cured (or reaction became too slow to observe any effect on the heat flux curve). In the isothermal step $\left(180^{\circ} \mathrm{C}\right)$ flux curve returns to zero level showing that there is no more thermal or chemical phenomena. Total heat of cure was determined by integration of the heat flux curve using a sigmoid baseline. The average value found is $\Delta \mathrm{H}_{\mathrm{avg}}=332 \mathrm{~J} / \mathrm{g}$ with $\mathrm{STD}=4.1$ and $\mathrm{CV}=1.9 \%$. This value is in agreement with DSC results. 


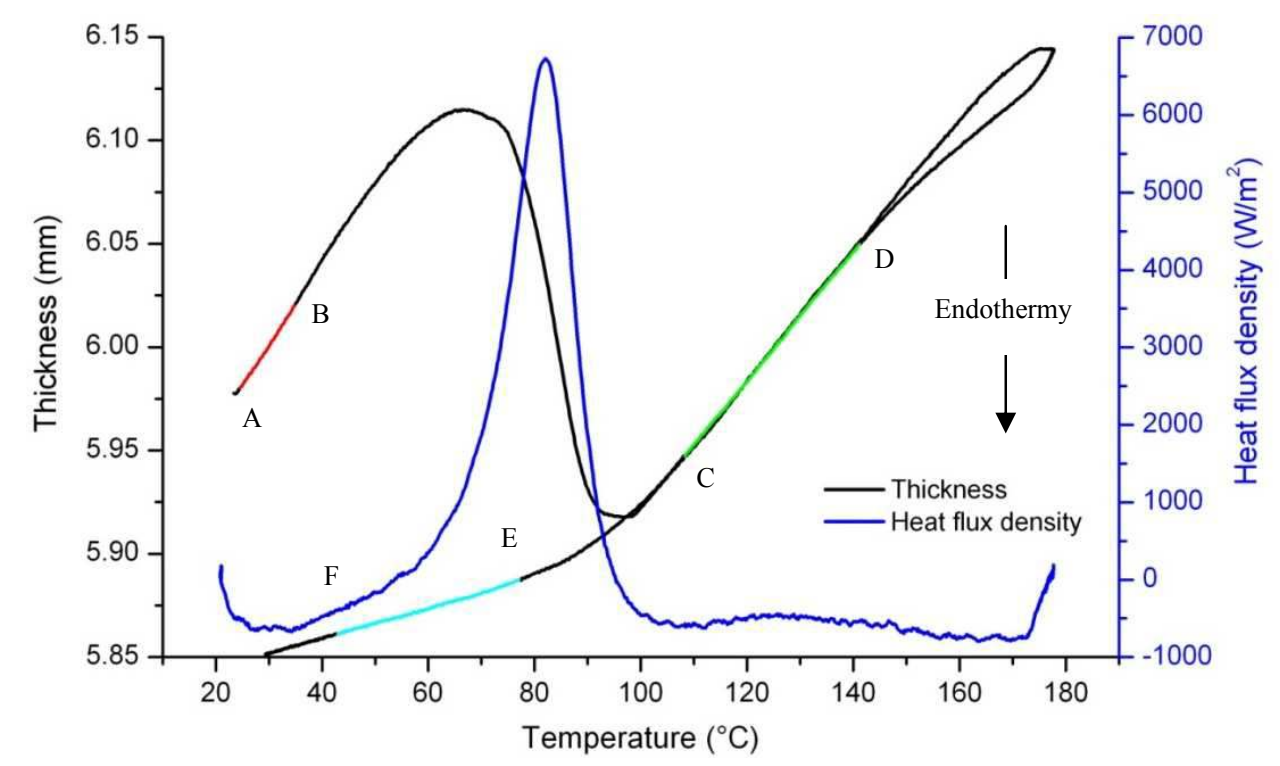

Fig. 2. Variation of thickness of neat resin sample and heat flux density versus temperature

If it is considered that sample temperature is equal to surface temperature, then its thermophysical properties and the crosslinking will also be uniform. Within this hypothesis, the calculation of the resin cure shrinkage becomes very simple by only subtracting the thermal contribution from the experimental thickness variation $[7,8]$. However, it is an approximation because it is rigorously necessary to take into account the temperature gradients through the sample thickness.

Calculation of shrinkage by considering the gradients. Due to rapid reaction kinetics, in thick thermoset resin/composite samples, the temperature difference between surface and sample core can be so high that it cannot be neglected. Thus, temperature and conversion degree fields, which depend on the sample thickness variation and coupled to reaction kinetics, have to be computed simultaneously during the curing cycle to deduce the exact contribution of thermal expansion and chemical shrinkage on the experimental displacement curve. Within this context, we describe heat transfer and volume variation (2a) coupled to crosslinking kinetics (2b). The used domain is cylindrical. Heat transfer is through the thickness, the sample being isothermal along the radius at a given thickness. Since $\rho, \mathrm{Cp}, \lambda$ depend on temperature and the degree of reaction, the problem to solve is non-linear. Initial temperature field (2e) is known, and boundary conditions are of the third kind $(2 c-d)$. The problem is given by the following set of equations where $h$ is the inverse of the thermal resistance induced by the silicone capsule and $\mathrm{T}_{\text {mould }}$ is the surface temperature of the mould cavity

$$
\left.\rho \operatorname{Cp}(\mathrm{T}, \alpha) \frac{\partial \mathrm{T}}{\partial \mathrm{t}}=\frac{\partial}{\partial \mathrm{t}}\left(\lambda(\mathrm{T}, \alpha) \frac{\partial \mathrm{T}}{\partial \mathrm{x}}\right)+\rho(\mathrm{T}, \alpha) \cdot \Delta \mathrm{H} \cdot \frac{\partial \alpha(\mathrm{T})}{\partial \mathrm{t}}, \mathrm{x} \in\right] 0, \mathrm{~L}[, \forall \mathrm{t}>0
$$

$\frac{\partial \alpha}{\partial t}=W(v(T)) \cdot K(T) \cdot G(\alpha) \cdot F_{\text {diffusion }}(\alpha)$

The kinetics of reaction are based on Bailleul model [9]. Where $W(v(T))$ is a function corresponding to the induction of reaction. $\mathrm{K}(\mathrm{T})$ is an Arrhenius function that describes the dependence of rate of reaction on temperature. $G(\alpha)$ is a polynomial function that determines the dependence of reaction rate on the degree of cure. $F_{\text {diffusion }}(\alpha)$ denotes the diffusion-controlled effects proposed by Chern and Poehlein [10].

$$
-\left.\lambda \frac{\partial \mathrm{T}}{\partial \mathrm{x}}\right|_{\mathrm{x}=0}=\mathrm{h}\left(\mathrm{T}_{\text {mouldl }}-\mathrm{T}\right), \mathrm{x}=0, \forall \mathrm{t}>0
$$


$-\left.\lambda \frac{\partial \mathrm{T}}{\partial \mathrm{x}}\right|_{\mathrm{x}=\mathrm{L}}=\mathrm{h}\left(\mathrm{T}-\mathrm{T}_{\text {mould } 2}\right), \mathrm{x}=\mathrm{L}, \forall \mathrm{t}>0$

$T(0, x)=T_{i n i}(x)$

In order to predict the temperature at each step of thickness, Crank-Nicholson method is used to discretize 1-D heat conduction equation. The object may be supposed to consist of numbers of slices (meshes), each having a volume $\mathrm{dV}$ with a thickness $\mathrm{dx}$, a surface area $\mathrm{S}$ and mass $\mathrm{dm}$. Due to shrinkage and thermal expansion, the volume of the mesh will change so the problem is a moving boundary one with constant slice mass. As temperature is varying through the thickness so all the meshes may not necessarily have the same volume (3)

$\frac{1}{d \rho_{i}(T, \alpha)}=d V_{i}(T, \alpha)=d V_{0_{i}}(1+\operatorname{CTE}(T, \alpha) \cdot \Delta T+\operatorname{CCS} . \Delta \alpha)$

where subscript $i$ is the number of a mesh, CCS is a coefficient of chemical shrinkage and $\Delta \mathrm{T}$ is the temperature difference with respect to initial temperature. Thermal expansion at any time is determined by using the identified values of CTE and temperature at each time step. The difficulty is to know the evolution of the volume shrinkage associated to resin crosslinking. Assuming the cure shrinkage is a linear function of $\alpha$ in each mesh for the neat resin (experimentally observed) and composite samples, we thus define a coefficient of chemical shrinkage (CCS) to describe this linear relationship and chemical shrinkage is identified to model the total thickness variation of each mesh. By iterative calculation, thickness of each mesh is calculated according to its temperature and degree of cure and then added to get final thickness at each time step.

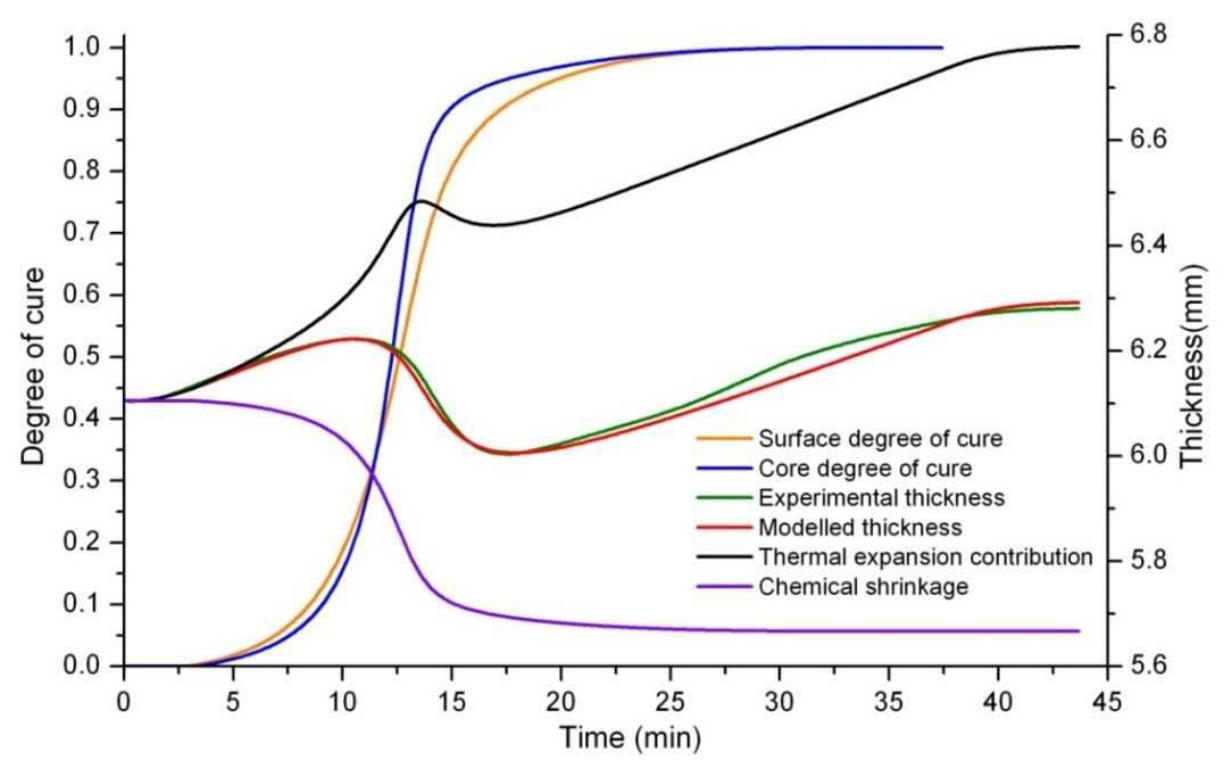

Fig. 3. Calculated thermal expansion and shrinkage contributions to the global displacement curve recorded for neat resin sample by considering temperature gradients.

In Fig.3. experimental displacement curve and the modelled one for the neat resin are plotted, after identification of CCS and CTE. Thermal expansion contribution curve represents the thickness of sample due to thermal expansion. Chemical shrinkage curve corresponds to the thickness evolution induced by resin crosslinking. From our calculations, the rapid kinetics lead to a temperature difference between the surface and the core of the sample which can reach about $20^{\circ} \mathrm{C}$ and justify our approach. This result explains the peak observed on the "thermal expansion contribution" curve. Indeed, it also induces a gradient of the degree of cure (up to 0.15 between the surface and the core of sample) since this parameter is strongly coupled to temperature field. 
Finally, the modelled curve superimposes very well the experimental thickness curve and validates the linear model to describe the resin cure shrinkage. The value of computed resin volume shrinkage was found equal to $-7.14 \mathrm{vol} \%$. The composite experiments were also treated similarly.

The modelling provides a good agreement between experimental and numerical curves. From the identified CCS values, the volume shrinkage induced by the crosslinking is equal to $-4.40 \mathrm{vol} \%$ for the $32 \mathrm{vol} \%$ fibre composite and $-2.76 \mathrm{vol} \%$ for $49 \mathrm{vol} \%$ fibres composite. The lower volume fraction of resin in composite samples leads to lower temperature and degree of cure gradients, as expected. The proposed shrinkage model, coupled to thermal effects can thus be used to simulate dilatometric behaviour of resin and associated composites. Finally, it is found that the curve of chemical shrinkage versus the mean conversion degree is non-linear, when thermal gradients are considered.

\section{Conclusion}

In the present work, mould PVT- $\alpha$ is used to determine the volume chemical shrinkage of vinylester resin and glass/vinylester composites [0/90] with two fibre volume fractions by considering the thermal gradients. The thermo-physical properties and the reaction kinetics resin were determined at first. Then the exact thermal expansion and chemical shrinkage contributions (which are coupled) to the sample volume variation during the curing were calculated by assuming a linear model for shrinkage evolution. The large heat of reaction, which is released in a short-time range, led to a thermal expansion peak and temperature and conversion degree gradient through the sample thickness for neat resin. The final resin chemical shrinkage value is found equal to $-7.1 \mathrm{vol} \%$. These observations are attenuated for composites since the volume fraction of resin is lower.

\section{Reference}

[1] C. Li, K. Potter, M.R. Wisnom, G. Stringer, In-situ measurement of chemical shrinkage of MY750 epoxy resin by a novel gravimetric method, Composites Science and Technology, 64 (2004) 55-64.

[2] N. Boyard, M. Vayer, C. Sinturel, R. Erre, D. Delaunay, Modeling PVTX diagrams: Application to various blends based on unsaturated polyester-Influence of thermoplastic additive, fillers, and reinforcements, Journal of Applied Polymer Science, 92 (2004) 2976-2988.

[3] J.V. Beck, B. Blackwell, C.S. Clair, Inverse Heat Conduction, Wiley-Interscience, New York 1985.

[4] S. David, Thermal conductivity of insulations using guarded hot plates, including recent developments and sources of reference materials, Measurement Science and Technology, 12 (2001) R89.

[5] J.L. Bailleul, D. Delaunay, Y. Jarny, Determination of Temperature Variable Properties of Composite Materials: Methodology and Experimental Results, Journal of Reinforced Plastics and Composites, 15 (1996) 479-496.

[6] J.-P. Pascault, R.J.J. Williams, H. Sautereau, Thermosetting Polymers, 4th ed., Marcel Decker Inc., 2002.

[7] Y. Nawab, N. Boyard, V. Sobotka, P. Casari, F. Jacquemin, A Device to Measure the Shrinkage and Heat Transfers during the Curing Cycle of Thermoset Composites, Advanced Materials Research, 326 (2011) 19-28.

[8] N. Boyard, A. Millischer, V. Sobotka, J.L. Bailleul, D. Delaunay, Behaviour of a moulded composite part: Modelling of dilatometric curve (constant pressure) or pressure (constant volume) with temperature and conversion degree gradients, Composites Science and Technology, 67 (2007) 943-954.

[9] J.1. Bailleul, Optimisation du cycle du cuisson de pièces épaisses en matériau composite. Application a un préimprégné résine époxide/ fibres de verre, in, $\mathrm{PhD}$ thesis, Université de Nantes, 1997.

[10] C.S. Chern, G.W. Poehlein, A kinetic model for curing reactions of epoxides with amines, Polymer Engineering \& Science, 27 (1987) 788-795. 